\title{
“Alfabetização" e "Letramento": construção de novos significados
}

\section{"Alphabetization" and "Literacy": construction of new meanings}

Nilce da SILVA

\section{RESUMO}

Este artigo se constitui por reflexão crítica feita no âmbito do "Grupo de Ensino, Pesquisa e Extensão Acolhendo Alunos em Situação de Exclusão Social e Escolar: o papel da instituição escolar" - certificado pela USP, com apoio do CNPq e FAPESP.

O mesmo pretende discutir as palavras mais usadas na área da Alfabetização, aqui chamadas de conceitos cotidianos, à luz das contribuições de Serge Wagner e de Jean Biarnès, de modo a contribuir para a compreensão deste processo tanto para educadores como para pesquisadores.

Faremos considerações acerca da necessidade da construção de novos sentidos neste âmbito do saber.

Palavras-chave: alfabetização, letramento, significados, usos sociais.

\section{ABSTRACT}

This article is constituted of a critical reflection in the scope of the "Group of Education, Research and Extension Receiving Pupils in a Exclusion Social and School Situation: the role of school as institution"certifyd by the USP, with support of CNPq and FAPESP. It intends to argue the words most used in the area of the Alphabetization, called "daily concepts" here, with Serge Wagner and Jean Biarnès' contributions in order to contribute in such a way for the understanding of this process for educators as for researchers. We will make considerations concerning the necessity of the construction of new felt in this scope of knowing.

Index Terms: alphabetization, literacy, meanings, social uses. 


\begin{abstract}
Oh, Thoth, mestre incomparável, uma coisa é inventar uma arte, outra é julgar os benefícios ou prejuízos que dela advirão para os outros! Tu, neste momento e como inventor da escrita, esperas dela, e com entusiasmo, todo o contrário do que ela pode vir a fazer! Ela tornará os homens mais esquecidos, pois que, sabendo escrever, deixarão de exercitar a memória, confiando apenas nas escrituras, e só se lembrarão de um assunto por força de motivos exteriores, por meio de sinais, e não de assuntos em si mesmos. Por isto, não inventaste um remédio para a memória, mas sim para a rememoração. Quanto à transmissão do ensino, transmites aos teus alunos, não a sabedoria, pois passarão a receber uma grande soma de informações sem a respectiva educação! Hão de parecer homens de saber, embora não passem de ignorantes, em muitas matérias e tornar-se-ão, por conseqüência, sábios imaginários, em vez de sábios verdadeiros.
\end{abstract}

(Platão)

\title{
Introdução
}

Durante os quatro anos da nossa atuação como docente da disciplina, em nível de graduação, "Metodologia do Ensino da Língua Portuguesa: a alfabetização", assim como, enquanto coordenadora do Grupo de Pesquisa, Ensino e Extensão "Acolhendo Alunos em Situação de Exclusão Social e Escolar: o papel da instituição escolar" - certificado pela instituição, com apoio CNPq e FAPESP, fundado em 2002 -, estivemos atentos aos “conceitos cotidianos" utilizados por graduandos, graduados, mestrandos e mestres, quando estes se referiam às pessoas em situação de pouca ou nenhuma escolarização e aos processos de ensino e de aprendizado da Língua Portuguesa, em diferentes ocasiões: debates e reflexões; conversas informais; e-mails; trabalhos acadêmicos; relatórios; diário de coleta de dados, relatórios de qualificação, dissertações, dentre outras. Consultamos, também, o material bibliográfico atual produzido e disponível acerca da temática em questão.

A partir do resgate escrito desta memória coletiva, verificamos que há uma série de palavras que são freqüentemente usadas no âmbito do ensino e da aprendizagem da Língua Portuguesa e que, quando em uso pelos 
diferentes sujeitos, não apresentam, necessariamente, consistência teórica entre si.

Pontuamos que muitas delas têm sido utilizadas entre aspas; concluímos que as mesmas poderiam estar em uso por falta de outras melhores; e, finalmente, que as representações ou sentidos atribuídos a tais palavras referem-se ao estado de um indivíduo, como se esta condição não pudesse ser alterada.

Tais observações sistemáticas, ao longo do tempo, fizeram-nos refletir sobre as palavras em uso para a compreensão do ensino da leitura e da escrita da Língua Portuguesa e da necessidade de construção de novos sentidos para as mesmas, tanto para professores como para pesquisadores, conforme demonstraremos neste artigo.

Para tanto, dividimos, em dois grupos, as palavras e as suas diferentes compreensões mais usadas pelos envolvidos nestas observações. O primeiro grupo é composto por palavras relacionadas ao “ALFABETIZAR", e o segundo, ao tema "LETRAR".

Em seguida, recorreremos aos conceitos propostos por Serge Wagner e Jean Biarnès - respectivamente: "analfabetismo de minoria", "analfabetismo de opressão", "analfabetismo de resistência", "alfabetização de afirmação nacional" - os quais remetemos diretamente ao nosso primeiro agrupamento e, ainda, ao "letrismo a-funcional" que compõe a teia semântica do segundo grupo aqui apresentado.

Finalmente, faremos as nossas considerações, que aproximam os respectivos grupos, na tentativa de construir conceitos e definições, ou ainda, outros sentidos para palavras tão ditas e escritas no cotidiano pedagógico.

\section{Dos sentidos atribuídos às "palavras" no âmbito do ensino e da aprendizagem da Língua Portuguesa}


$\mathrm{Na}$ perspectiva assinalada acima, apresentaremos, a seguir, as "palavras" mais usadas pelos sujeitos desta observação. Destacamos 12 "palavras", que foram agrupadas em dois grupos: 1. Grupo ALFA; e 2. Grupo LETRA ou LITERA.

Vejamos a composição destes grupos:

Grupo ALFA: Alfabetização, alfabetizado, alfabetismo, alfabetização funcional, analfabetismo, analfabeto, analfabeto funcional e semi-analfabeto.

Grupo LETRA: Literacia, letramento, letrado, letrado funcional e iletrado.

Cada uma destas palavras recebeu, ao longo do período sistematizado, diversas, porém, semelhantes "definições/sentidos".

Vejamos as palavras pertinentes ao primeiro agrupamento:

Para o conceito de "alfabetização", deparamo-nos com as seguintes compreensões/definições: a. "ensino da leitura e da escrita"; b. "ensino da lectoescrita"; c. "estratégia de libertação que ensina as pessoas não só a lerem as palavras, mas especialmente o mundo"; d. "aprender a ler e a escrever em sua língua materna"; e. "processo de aquisição individual de habilidades requeridas para a leitura e escrita"; f. "processo de representação de objetos reais diversos"; g. "processo de aprender a ler e a escrever que tem um fim"; h. "processo de aprender a ler e a escrever que nunca tem fim"; i- "processo de aquisição da escrita por um indivíduo"; e j. "também pode ser chamado de literacia".

O "alfabetizado" foi tratado como pessoa que "é capaz de ler e escrever"; "usa a leitura como um meio de conscientização da realidade"; "tem domínio do código alfabético"; "é capaz de ler e escrever corretamente uma palavra ou uma frase"; "sabe ler e escrever, ler, escrever e contar"; "freqüentou a escola"; "somente aprendeu a ler e a escrever". Assim, o "alfabetismo" "é um estado ou qualidade de alfabetizado". 
A "alfabetização funcional" indica "a possibilidade de usar a escrita e a leitura em determinadas tarefas do dia-a-dia"

Com relação ao "analfabetismo", registramos que é a "incapacidade de ler ou escrever em uma língua"; "incapacidade de ler e escrever na vida diária", "falta de escolaridade", "é um estado ou modo de proceder como analfabeto".

Do mesmo modo, o "analfabeto" foi considerado como pessoa que "não teve oportunidade de aprender a ler e a escrever"; "não se apropriou do saber da leitura e da escrita"; "não possui a tecnologia da decodificação dos signos lingüísticos"; "não sabe ler e escrever, mas possui certo grau de letramento pela experiência em uma sociedade letrada, que tem escrita".

Já o "analfabeto funcional" representa uma pessoa que "não se vira direito na sociedade porque não sabe ler e escrever direito"; "é um semianalfabeto"; "não sabe escrever uma carta, um bilhete, anotar um recado"; "identifica apenas informações explícitas em textos muito curtos"; "somente consegue ler textos curtos e sem complexidade"; "não tem fluência da leitura"; "é um leitor cujo nível de fluência não é funcional para o contexto em que a leitura ou escrita é requerida"; "pessoa incapaz de ler e escrever, compreendendo, um relato simples e breve de acontecimentos relacionados com sua vida quotidiana".

Com relação ao "semi-analfabeto", obtivemos os seguintes sentidos: "é uma pessoa que consegue ler coisas muito fáceis"; "só consegue ler textos curtos e sem dificuldade"; "são pessoas que enfrentam dificuldades para escrever um ofício, preencher um formulário, registrar a candidatura a um emprego, preencher uma folha de talão de cheque, por exemplo"; "é aquele que só sabe assinar o nome"; "pessoas que encontram dificuldade para decodificar os signos lingüísticos, mas são incapazes de estabelecer relações de sentido"; "pessoas que tem menos de quatro anos de estudo";

No que diz respeito ao segundo grupo aqui elaborado - Grupo LETRA, foi associado o termo "literacia" definido como "processo de 
aquisição da língua escrita que permite a uma pessoa se orientar nas atividades do cotidiano"; "corresponde a uma tradução da palavra em inglês literacy"; "o termo literacia está associado a palavras como literato ou letrado e diz respeito ao conhecimento literário ou hábito de ler de uma pessoa"; "a capacidade de usar todas as formas de material escrito requeridos pela sociedade e usados pelos indivíduos que a integram"; "a capacidade de utilização da língua escrita"; "capacidades de processamento de informação escrita na vida quotidiana"; "vai da identificação de sinais gráficos de uso quotidiano à decifração de textos mais difíceis"; "é um processo de conhecimento sempre aberto"; "literacy, com a representação etimológica de estado, condição, ou qualidade de ser literate, e literate é definido como educado, especialmente, para ler e escrever".

Além disto, para o "letramento", anotamos os seguintes sentidos: "não é apenas saber ler e escrever, é mais do que isto: é saber fazer uso do ler e do escrever, saber responder às exigências de leitura e de escrita que a sociedade faz"; "resultado da ação de ensinar a ler e a escrever de uma pessoa e como ela se apodera desta escrita e como usa esta escrita em sociedade"; "focaliza os aspectos sócio-históricos da aquisição de um sistema escrito por uma sociedade"; "é fenômeno de cunho social, e salienta as características sócio-históricas ao se adquirir um sistema de escrita por um grupo social"; "não ocorre apenas no sistema escolar"; "pode ser uma das funções da escolar: letrar as pessoas"; "é uma abordagem que procura compreender a leitura e a escrita como práticas sociais complexas, desvendando sua diversidade, suas dimensões políticas e ideológicas”.

O "letrado", nos nossos registros, é considerado como pessoa que "tem grande conhecimento literário"; "tem o hábito da leitura”; "é versada em letras"; "é erudito"; "passou pelo processo de "letramento"; "nasceu em sociedade letrada".

Foi considerado como "iletrado": "quem não tem conhecimentos literários; "um analfabeto ou quase"; "quem é capaz de ler e escrever, 
contudo, não possui habilidades para práticas que envolvem a leitura e a escrita: não lê revistas, jornais, informativos, manuais de instrução, livros diversos, receita do médico, bulas de remédios"; "aquele que tem grandes dificuldades para interpretar textos lidos e não consegue escrever uma carta ou bilhete"; "pessoa que sabe ler, mas não entende aquilo que leu";

Ao analisarmos estes dois grupos de conceitos cotidianos, vale a pena ressaltar que uma mesma pessoa usa tanto palavras do grupo um como do grupo dois, ou, até mesmo, todas as palavras que apresentamos, sem nenhuma restrição. Muitas vezes, para uma ou outra palavra, como, por exemplo, "analfabeto" ou "alfabetizado", as mesmas, quando em texto escrito, aparecem entre aspas, e, quando pronunciadas, apareceram acompanhadas pelos gestos das mãos que indicam a referida marcação gráfica.

Notamos também que todos estes termos são usados no sentido de "fato acabado"; "situação definitiva ocupada por uma pessoa", e não como um "processo", ou "como um momento da vida de uma pessoa".

Entretanto, apesar destas pequenas observações que denotam, aparentemente, uma certa inconsistência de quem as usa, os sentidos atribuídos e registrados no âmbito deste trabalho "iluminam", do nosso modesto ponto de vista, apenas parcialmente, a prática pedagógica daquele que quer ensinar a ler e a escrever, e o "aprendizado" dos alunos em situação de pouca ou nenhuma escolarização. Por isso, recorremos aos conceitos de Serge Wagner e de Jean Biarnés no sentido de, independentemente da correção ou não dos sentidos registrados sobre os termos mais usados, re-significar parte deste quadro conceitual que tem sido usado correntemente, como se a sociedade não fosse composta por diferentes grupos e subgrupos culturais na área educacional.

Os respectivos professores apresentam e definem os seguintes conceitos: "letramento a-funcional" (Jean Biarnès); e "analfabetismo de 
opressão"; "analfabetismo de resistência", e "analfabetismo de afirmação nacional" (Serge Wagner).

\section{Tecendo sentidos da "alfabetização" e do "letramento"}

O professor canadense Serge Wagner, já em 1990, apresenta-nos conceitos muito interessantes, pois acompanham o termo "alfabetização" e tecem sentidos a este, refinando-o e, por isso, permitem trabalhos mais precisos junto com minoria lingüísticas no âmbito do ensino, da pesquisa e da extensão. São eles: a- "analfabetismo de minorias"; "analfabetismo de opressão"; "analfabetismo de resistência"; e "alfabetização de afirmação nacional". Vejamos as definições propostas no L.I.R.E. les actes $d u$ Colloque: culture et subcultures orales, cultures et subcultures de l' ecrit dans le pays de la francophonie.

Para compreendermos as suas definições, é importante levarmos em consideração como este autor define "minoria lingüística", pela sua composição, a saber: 1- Povos aborígenes: grupo de pessoas que se encontram no local há muito tempo e que podem ser considerados os "primeiros" habitantes da terra: indígenas no Brasil. 2- Minorias estáveis: grupos que se estabelecem no local há muito tempo e que mantêm certas diferenças com a população local: catalões na Espanha. 3- Novas Minorias: grupos recém-chegados na nova localidade, chamados também de migrantes: nordestinos em São Paulo.

Para Wagner (1990), quando uma minoria lingüística se vê em contato com uma língua majoritária, dominante em determinado local, existem duas formas de manifestação do "analfabetismo": o "analfabetismo de opressão" ou o "analfabetismo de resistência". Este é uma reação de um grupo de pessoas, que recusa o processo de assimilação, ou, ainda, de aculturação proposto. Pontuamos que esta "recusa" pode se dar do mais consciente até o inconsciente, com o objetivo de salvaguardar a cultura de 
origem da parte "mais fraca" da sociedade em questão. Nesta direção, quando ocorre esta modalidade de "alfabetização", a pessoa, ou o grupo, pode reivindicar o direito de aprender a escrita e a leitura de sua própria língua, quando esta possui versão escrita; e caso esta língua não possua escrita, o grupo, ou pessoa, torna-se "duplamente analfabeto", pois não pode aprender a língua que gostaria e não aprende a língua majoritária.

Por outro lado, o "analfabetismo de opressão" tende a se desenvolver quando a minoria em questão é obrigada a aprender a língua do grupo dominante, seja pelo sistema público de ensino, seja pela necessidade de inserção no mercado de trabalho. Para Wagner (1990), neste caso, ao longo do tempo, a cultura da minoria, em processo de alfabetização na língua do outro, desaparece. Temos as minorias que freqüentam escolas públicas, onde são "obrigadas" a aprender a língua do grupo social dominante. Tal situação de "obrigação" provoca, para o estudioso canadense, todos os tipos de efeitos pedagógicos. Dentre eles, destacamos: "o aluno pertinente à minoria fica defasado"; "o aluno perde sua língua de origem e aprende mal a língua dominante por meio da qual ele deve pensar, agir, trabalhar", e, ainda, "um sujeito mal equipado do ponto de vista lingüístico".

O outro conceito de Serge Wagner (1990) que destacamos é o de "alfabetização de afirmação nacional", que significa o aceitamento do aprendizado de uma língua, que não é a sua língua materna, sabendo que este processo deve ocorrer para determinados fins de afirmação do seu país, e de si mesmo, porém, tal aprendizado não significa romper com suas raízes. Ou seja, é uma alfabetização que significa o "aprender mais uma língua", que nada se relaciona com o abandono da sua própria. Wagner ressalta termos decorrentes desta situação social: "alfabetização de afirmação comunitária" e "alfabetização de afirmação individual". Finalmente, não obstante esta "aceitação", caso estas minorias venham a manter sua língua materna, sempre em paralelo com a do grupo dominante, por meio de 
instâncias institucionalizadas, com o passar dos anos, uma situação de separatismo político-administrativo pode ocorrer.

Conforme procuramos demonstrar, as considerações de Wagner alargam, ao mesmo tempo em que definem e refinam, os dados coletados que apresentamos no grupo ALFABETIZAR. Wagner, também, detém-se especialmente em aspectos objetivos do fenômeno, sejam eles em nível pessoal, ou comunitário ou de nação, em termos do aprendizado ou não de determinada língua. Neste ponto, o leitor poderia nos questionar: e o grupo $\mathrm{B}$, apresentado acima, como se relaciona com o A, levando em consideração os conceitos propostos por Wagner? Respondemos que Jean Biarnés, da Universté Paris Nord, fará este trabalho de ampliar e refinar os conceitos contidos em B, e ligá-los aos termos da teia "ALFABETIZAR", quando investiga e constata que a recusa ao aprendizado da língua majoritária pode se dar em nível inconsciente.

No artigo, $O$ ser e as Letras: da voz à letra, um caminho que construímos todos, Biarnés (1998) afirma que cada um de nós constrói uma relação com o mundo das letras e, por meio desta relação, constrói-se a si mesmo. Ou seja, ninguém está fora deste mundo e, mais do que isto, ele atribui e re-atribui sentidos para esta relação ao longo da vida. Vejamos abaixo diferentes passagens deste artigo, que juntas nos dão clareza acerca da relação entre Homem e letra:

A letra me permite encontrar o outro, encontrar a alteridade e, sobretudo, construir 'meu outro' em mim. A letra, objeto do outro se a leio, objeto para o outro se a escrevo, é um espelho mágico que me permite reconhecer-me, descobrindome outro. O problema do acesso à leitura, como o da iniciação à escrita, está aí. Para que, pela letra, eu possa conhecer-me outro, é necessário que eu possa antes reconhecer-me nela [...] Construir uma relação de funcionalidade com a letra é ser em vir-a-ser. Mas ser em vir-a-ser implica um duplo movimento: abandonar o presente e construir o futuro, 'fazer não ser o meu ser e ser um não-ser' [....] A funcionalidade da letra não é saber preencher o formulário da Previdência, ou saber responder ao questionário da assistente social, ou da apostila do professor. Propor esse tipo de exercício em um estágio de formação, ou na escola, é um non-sens?, se o exercício não servir de 
estímulo à leitura do livro. A funcionalidade da letra é ser capaz de descobrir o segredo contido no livro! Só se aprende ou se reaprende a ler nos livros! Foi isso, exatamente, que nos mostrou aquela pessoa que tinha "falado de literatura" com sua professora. Só a letra do livro pode deslocar o sujeito de sua aderência ao espaço-tempo de seu meio, daquela "imagem do mesmo", e abrir, então, o espaço do jogo onde a letra tem sentido.

Sendo assim, do nosso ponto de vista, tanto o primeiro grupo como o segundo, de significados atribuídos aos conceitos usados na área da alfabetização, precisam ser complementados, para que possam referir-se ao aprendizado da Língua Portuguesa por minorias lingüísticas; no caso deste projeto, por migrantes nordestinos, na cidade de São Paulo, e pelos diferentes grupos étnicos que compõem a atual sociedade moçambicana.

\section{Considerações finais}

Na medida em que, como expusemos, neste artigo não tivemos, nem temos, a intenção de verificar a consistência das compreensões, em uso, dos termos em questão, assim como não procuramos o(s) referencial(ais) teórico(s) subjacente(s) aos mesmos, nem mesmo procuramos estabelecer relações entre as compreensões registradas, consideramos as seguintes questões acerca do aprender a ler e a escrever a língua oficial e padrão de determinado país por minorias etnolingüísticas, tais como "migrantes nordestinos em São Paulo"; "falantes do francês em algumas regiões do Canadá”; "aos diferentes grupos indígenas no Brasil, no México, na Bolívia, dentre outros"; "aos imigrantes latinos na Europa ou nos Estados Unidos"; e, ainda, "às diferentes etnias que compõem os países africanos".

Salientamos, entretanto, que os referidos grupos são minorias, apenas no sentido de que não (de)têm "poder", pois, numericamente, tendem a superar a "outra parte" da população do país em questão. Nesta direção, justamente por serem "minorias", não são ouvidos, muitas das vezes, inclusive, por nós pesquisadores. 
No quadro social brasileiro, marcado por extrema desigualdade e injusta distribuição de renda, especialmente as minorias sociais, conforme todos sabemos, são compostas pelos membros mais pobres da nossa população, e compõem o corpo discente das escolas públicas de Ensino Fundamental. Dito de outro modo, são os descendentes de indígenas e ou negros, migrantes basicamente em direção aos grandes centros, que compõem este contingente que, notoriamente, tem desempenho escolar insatisfatório, ou seja, que não aprende a ler e a escrever.

Por isso, consideramos que, antes de categorizarmos esta ou aquela pessoa, seja do ponto de vista da sua subjetividade, ou da relação aparente/ externa que mantém com a letra; antes de atribuirmos juízos de valor a este ou àquele conceito, precisamos levar em consideração alguns aspectos sobre os quais discorreremos a seguir.

Os sentimentos que as pessoas têm, quando em relação com a letra. Ou seja, precisamos perguntar às crianças, aos jovens e aos adultos: Como você se sente ao ler um texto? Qual é o sentimento que você tem quando tentam lhe ensinar a Língua Portuguesa? Feliz? Triste? Incomodado? Nervoso? Insatisfeito? Invadido? Traído?

Na medida em que hoje eu posso não aprender, e amanhã, a possibilidade para tal ainda existe, não há como se falar em "tal pessoa é letrado", ou "analfabeto", ou qualquer outro predicativo. Ela "está em". E, salientamos, mesmo este "estar" pode ser uma "representação", na concepção de Goffman. Os sujeitos que investigamos podem, sim, representar um estado de analfabetismo funcional, ou não? Podem representar que dominam a letra e a escrita em tal e tal situação, ou não? Sabemos nós, pesquisadores, quando eles se "mascaram"?

Ou seja, ANTES de falarmos, usando "esta" ou "aquela palavra" sobre as pessoas que, aparentemente, estejam em situação de aprendizado da Língua Portuguesa, precisamos saber, de fato, quem são eles e o que eles pensam, caso eles queiram nos mostrar. 
Nesta mesma direção, questionamos: quais os benefícios sociais que uma pessoa encontra, caso seja chamada de "analfabeto"? Nenhum? Não acredito nesta possibilidade. Há sempre que se relativizar. Precisamos perguntar para estes, que já receberam este "título" no seio da sociedade grafocêntrica em questão, se obtiveram o que queriam em nossa sociedade. Suponha, por exemplo, uma mulher que quer sair de casa à noite, pois não suporta a rotina doméstica. Acaso, não é interessante para ela dizer para sua família que não sabe ler e escrever, de modo a poder freqüentar uma sala de EJA?

Acrescentamos, ainda, que, do ponto de vista social, não querer aprender a Língua dominante, com o passar do tempo, significa a possibilidade da criação de um novo Estado, autônomo. Não é esta a situação da parte canadense que fala francês? Ou da parte da Espanha que fala catalão? Ou seja, será que a grande recusa, praticamente em massa, de alunos brasileiros que não aprendem e/ou mostram que não aprendem, ou não querem aprender, não é o embrião de um futuro e Novo Estado Nacional?

Ou seja, é um direito não querer aprender isto ou aquilo. Sendo assim, é legítimo que nossos alunos não queiram aprender. Ou não?

Há que se acrescentar que uma pessoa pode receber esta ou aquela denominação, dependendo do grupo em que está inserido. Ou, ainda, um determinado aluno que na escola é considerado ou chamado de "semianalfabeto", na comunidade em que vive pode ser aquele que sabe mais da leitura e da escrita, e não receberia esta categorização.

Entretanto, e, não menos importante, até onde conhecemos, todos estes conceitos foram construídos tendo como pressupostos: a vontade de aprender, por TODA pessoa de qualquer sociedade que tem leitura e escrita; apenas as vantagens e os benefícios em saber ler e escrever na Língua Oficial de um país por uma sociedade feita de grupos e subgrupos culturais; e, ainda, que as pessoas estão na escola para aprender. Não parece que 
estamos sendo ingênuos? Nós, escritor e leitor, temos ido a uma escola sempre com o objetivo de aprender? Por que os sujeitos das nossas investigações têm que ir à escola necessariamente para aprender? Eles não podem resistir? Eles não podem não querer?

E, ainda, caso aceitemos esta realidade como opção - a de NÃO querer aprender a Língua Portuguesa -, seja porque isto não interessa para os seus planos futuros, seja porque se sente mal nesta situação, não teremos nós, os que sabem ler e escrever sobre algo, que aprender a respeitar o "outro"?

Sabemos que estes questionamentos estão apenas na dimensão consciente do ser humano, do controlável ou quase controlado. Porém, como bem nos assinalou Freud, e, neste artigo, Biarnès (1998) nos alertou, existem TODOS os aspectos do Inconsciente envolvidos na questão. E, neste âmbito, nós, pesquisadores ou professores da área da Alfabetização, temos muito menos propriedade para falar sobre nossos alunos ou sujeitos.

Ainda, do nosso ponto de vista, as palavras, aqui chamadas de "conceitos cotidianos", iluminam, de modo mais amplo, as questões referentes à alfabetização, levando em consideração o olhar daquele que ensina. As mesmas, para que representem, de fato, a realidade daquele que aprende - da minoria não ouvida -, precisam ser usadas em "menor escala", pois o aceitar ser alfabetizado ou não é uma posição, consciente ou não, ou é uma decisão individual; "cada caso será um caso". Ou seja, podemos falar, usando as palavras tanto do primeiro grupo aqui apresentado quanto do segundo, se nos referimos ao processo de ensino da Língua Portuguesa excelência da Didática - e não do aluno, daquele que aprende - preocupação da Psicologia, Sociologia, dentre outras áreas. Reiteramos, assim, que estes são dois processos distintos, inúmeras vezes tomados equivocadamente como único. Estes dois termos, como afirmam alguns, não formam um par “causa/ conseqüência”, como é “comprar e vender”. Aquele que ensina a ler e a escrever não pode garantir a aprendizagem do outro. 
Finalmente, há que se ressaltar a inconstância da existência humana e de seus processos de aprendizagem. As pessoas estão em situação de alfabetização, estão em situação de alfabetizado. Jamais podemos afirmar que são "alfabetizados", pois, um pequeno acidente físico pode tirar a pessoa desta situação e ela se tornar uma pessoa em situação de analfabetismo. Ou, no movimento inverso, hoje, um aluno pode não ler e escrever, ou ainda, estar em situação de analfabetismo, e, amanhã, devido a processos que necessitam ser investigados, este indivíduo pode estar em situação de analfabetismo funcional, situação que, obviamente, também pode ser alterada.

Em suma, afirmamos que precisamos tecer nossos conceitos na área da Alfabetização, levando em consideração seis características do ser humano: 1. a História dos povos e os resultados de histórias pessoais a longo prazo; 2. O ser e a "representação" do ser; 3. A volição: o querer ou não aprender; 4. O inconsciente desconhecido; 5. As diferenças entre o “ensinar" e o "aprender"; e 6. A impermanência do "eu”. Só assim, se observamos estas características, e, através delas, re-significarmos os conceitos cotidianos aqui discutidos, os mesmos poderão contribuir para a área da Alfabetização.

\section{Referências bibliográficas}

(1998). O Ser e as Letras: da voz à letra, um caminho que construímos todos. In: Revista da Faculdade de Educação, v. 24, n. 2, São Paulo, jul/dez.

BIARNÈS, Jean (1999). Universalité, Diversité, sujet dans l'espace pédagogique. Paris: L'Harmattan.

WAGNER, Serge (1990). Minorites Ethnolinguistiques, analhabetisme et alphabetization: les francophones minoiritaires au Canada. LIRE les Actes fu Colloque. Paris, p.113-131. 


\section{Autora}

\section{Nilce da Silva}

Pós-Doutorado na Universitè Paris Nord, Paris, França; doutorado sanduíche na Universidade de São Paulo e Universitè Paris Nord. Docente, pesquisadora e orientadora nas áreas de "Linguagem e Educação" e "Psicologia e Educação" na Faculdade de Educação da Universidade de São Paulo (FEUSP). //Telefone: (11) 3091-3099// Av. da Universidade, 308. Butantã. CEP: 05508-900// nilce@usp.br

\section{Como citar este artigo:}

SILVA, Nilce da. "Alfabetização" e "Letramento": construção de novos significados. Revista ACOALFAplp: Acolhendo a Alfabetização nos Países de Língua portuguesa, São Paulo, ano 1, n. 1, 2006. Disponível em: <http://www.acoalfaplp.net>. Publicado em: setembro de 2006. 